Pesq. Vet. Bras. 35(11):919-924, novembro 2015 DOI: 10.1590/S0100-736X2015001100008

\title{
Ultrassonografia abdominal de tamanduás-bandeira (Myrmecophaga tridactyla Linnaeus, 1758) mantidos em cativeiro ${ }^{1}$
}

\author{
Érika R. Lopes ${ }^{2}$, Thaís O. Morgado ${ }^{3}$, Yara S. Meireles ${ }^{2}$, Adriano A. Jorge ${ }^{4}$, Arielli A.Q. \\ Zago $^{2}$, Sandra H.R. Corrêa ${ }^{3}$, Regina C.R. da Paz ${ }^{5}$ e Pedro B. Néspoli*
}

\begin{abstract}
Lopes E.R., Morgado T.O., Meireles Y.S., Jorge A.A., Zago A.A.Q., Corrêa S.H.R., Paz R.C.R. \& Néspoli P.B. 2015. [Ultrasound in anteaters (Myrmecophaga tridactyla Linnaeus, 1758) in captivity.] Ultrassonografia abdominal de tamanduás-bandeira (Myrmecophaga tridactyla Linnaeus, 1758) mantidos em cativeiro. Pesquisa Veterinária Brasileira 35(11):919-924. Setor de Diagnóstico por Imagem, Faculdade de Agronomia, Medicina Veterinária e Zootecnia, Universidade Federal do Mato Grosso, Av. Fernando Corrêa da Costa 2367, Bairro Boa Esperança, Cuiabá, MT 78060-900, Brazil. E-mail: nespoli@ufmt.br

Ultrasonography is a method of non-invasive imaging and an important tool for diagnosing a variety of animal diseases. In this paper the technique of transabdominal ultrasonography in five anteaters (Myrmecophaga tridactyla), two males and three females, belonging to the Federal University of Mato Grosso Zoo and a necropsy of an animal dead for natural cause were performed. The Zoo animals were anesthetized with tiletamine and zolazepan (Zoletil@) and maintained with isoflurane. Linear multifrequency transducer (LA 332) of the 3.0 to $11 \mathrm{MHz}$ scans of the liver, gallbladder, stomach, spleen, kidneys, bladder and testes. There are similarities between the splenic architecture, the liver texture and echogenicity and the gallbladder ultrassonografic position and appearance when compared to the canines. Differences exist as renal and testes location, stomach wall thickness and presence of free anechoic fluid among the stomach, spleen and left kidney in all animals studied.
\end{abstract}

INDEX TERMS: Ultrasonography, abdomen, morphology, Myrmecophaga tridactyla, anteater, ultrasound.

RESUMO.- A ultrassonografia é um método de imagem não invasivo e uma ferramenta importante para o diagnóstico de uma variedade de enfermidades de animais. Neste trabalho foi realizada a técnica de ultrassonografia transab-

\footnotetext{
${ }^{1}$ Recebido em 15 de janeiro de 2015.

Aceito para publicação em 20 de agosto de 2015.

${ }^{2}$ Setor de Diagnóstico por Imagem, Hospital Veterinário (Hovet), Universidade Federal do Mato Grosso (UFMT), Avenida Fernando Corrêa da Costa 2367, Bairro Boa Esperança, Cuiabá, MT 78060-900, Brasil. E-mails: erika_rondon10@hotmail.com, yarameireles@gmail.com, ariellizago@ hotmail.com; *Autor para correspondência: nespoli@ufmt.br

${ }^{3}$ Setor de Clínica de Animais Silvestres, Hovet-UFMT, Av. Fernando Corrêa da Costa 2367, Bairro Boa Esperança, Cuiabá, MT 78060-900. E-mail: thaismorgado@gmail.com

${ }^{4}$ Centro Cirúrgico, Hovet-UFMT, Av. Fernando Corrêa da Costa 2367, Bairro Boa Esperança, Cuiabá, MT 78060-900. E-mail: adrianoalvesjorge @hotmail.com

${ }^{5}$ Departamento de Ciências Básicas e Produção Animal, Faculdade de Agronomia e Medicina Veterinária, UFMT, Av. Fernando Corrêa da Costa 2367, Boa Esperança, Cuiabá, MT 78060-900. E-mail: reginacrpaz@gmail.com
}

dominal em cinco tamanduás-bandeira (Myrmecophaga tridactyla), dois machos e três fêmeas, pertencentes ao Zoológico da Universidade Federal de Mato Grosso e acompanhada a necrópsia de um animal morto de causas naturais. Os animais do zoológico foram anestesiados com Tiletamina e Zolazepam (Zoletil@) e mantidos em plano anestésico com Isofluorano. Foram realizadas varreduras com transdutor linear (LA332) multifrequencial de 3,0 a $11 \mathrm{MHz}$ do fígado, vesícula biliar, estômago, baço, rins, bexiga e testículos. Os resultados obtidos mostram que existem semelhanças entre a arquitetura esplênica, a textura e ecogenicidade hepática, a posição e a aparência ultrassonográfica da vesícula biliar quando comparado com a dos caninos. Existem diferenças como localização renal, localização dos testículos, espessura da parede do estômago e presença de liquido livre anecóico entre o estômago, baço e rim esquerdo em todos os animais estudados.

TERMOS DE INDEXAÇÃO: Ultrassonografia, abdome, morfologia, Myrmecophaga tridactyla, tamanduá-bandeira, ultrassom. 


\section{INTRODUÇÃO}

A ultrassonografia é bastante eficaz na identificação de alterações do trato reprodutivo, urinário, digestivo, tanto de animais domésticos quanto de silvestres, e auxilia no estabelecimento de diagnósticos clínicos e medidas terapêuticas mais efetivas. Trata-se de um método não invasivo, preciso, de rápida mensuração e pode ser empregado em quaisquer condições no monitoramento de animais capturados (Hildebrandt \& Göritz 1998, Hildebrandt et al. 2000).

0 tamanduá-bandeira (Mymercophoga tridactyla), apesar de estar distribuído por toda América Central e do Sul, vem sendo encontrado mais comumente em áreas de Cerrado (Bartmann 1994), e figura como espécie ameaçada de extinção do Ministério do Meio Ambiente (Ibama 2003) e é considerada espécie vulnerável por instituições internacionais (Iucn 2007).

Assim como ocorre com outras espécies silvestres importantes da nossa fauna e apesar de estarem disponíveis alguns estudos anatômicos específicos (Bartmann et al. 1991, Naples 1999, Endo et al. 2007, Souza et al. 2010), ainda não existem estudos sobre a anatomia ultrassonográfica das estruturas abdominais destes animais. Este trabalho foi realizado com intuito de trazer informações básicas sobre essa morfologia ultrassonográfica, para servir de parâmetro inicial no diagnóstico de afecções através desse método, e contribuir indiretamente para a preservação dessa espécie.

\section{MATERIAL E MÉTODOS}

Para este estudo foi utilizado cinco tamanduás bandeira (Myrmecophaga tridactyla Linnaeus 1758) adultos, dois machos e três fêmeas do Zoológico da Universidade Federal do Mato Grosso (UFMT), campus Cuiabá- MT com aprovação do comitê de Ética em Pesquisa Animal (CEPA) em 16 de junho de 2011, sob número do protocolo 23108.022075/11-7 e realizada necropsia de um Tamanduá morto de causas naturais. Alguns desses animais nasceram em cativeiro, outros ingressaram no Zoológico ainda filhotes por serem órfãos ou por consequência de atropelamento. 0 peso dos machos estudados foi de aproximadamente $40,3 \mathrm{~kg}$ e o das fêmeas de $45 \mathrm{Kg}$.

Os animais foram submetidos a jejum sólido e hídrico de 12 horas e capturados nos seus recintos por meio de puçá. Como medicação pré-anestésica (MPA) intramuscular foi usada a associação de Tiletamina e Zolazepan (Zoletil@) na dose de 3-5mg/ kg respectivamente e para manutenção anestésica foi usado o Isofluorano.

Para a realização dos exames ultrassonográficos, os animais foram contidos em decúbito dorsal, a superfície abdominal foi tricotomizada e o abdome escaneado após aplicação do gel para ultrassonografia com aparelho My Lab Five da marca ESAOTE, equipado com transdutor linear (LA 332) multifrequêncial de 3,0 a $11 \mathrm{MHz}$.

Foi avaliada a morfologia das vísceras abdominais como bexiga, rins, fígado, baço, estômago e testículos.

Durante o período de contenção química e o período de recuperação da anestesia foram monitoradas as frequências cardíacas, respiratórias e temperatura retal dos animais até que os mesmos pudessem voltar aos seus recintos.

Os exames foram realizados por ultrassonografista experiente nas dependências do Zoológico da Universidade Federal do Mato Grosso, com tempo médio de aproximadamente vinte minutos.
As imagens obtidas foram avaliadas por três ultrassonografistas, comparando a morfologia dos animais estudados entre si e com a aparência ultrassonográfica descrita para caninos domésticos. Foram consideradas nessa avaliação a morfologia, localização, estruturas anatômicas e a correlação entre os órgãos.

\section{RESULTADOS}

Os cinco tamanduás bandeira, dois machos e três fêmeas apresentaram bom estado nutricional e parâmetros clínicos dentro da normalidade. 0 fígado desses animais foram escaneados na porção mais cranial do abdome, entre a superfície diafragmática e o estômago, sempre limitados caudalmente pelo gradil costal. Nas varreduras longitudinais a maior porção do órgão foi detectada do lado direito, com volume decrescente à medida que se aproximava do lado esquerdo do abdome. Não foi possível escanear o fígado no mesmo plano que o rim direito, porém, houve facilidade de incluir na mesma varredura o fígado e o baço pelo lado esquerdo. 0 órgão apresentou formas e contornos regulares, ecotextura média, homogênea, com hipoecogenicidade leve em relação ao baço. (Fig.1A,B). A vesícula biliar foi detectada em varreduras longitudinais e transversais, levemente a direita da linha média com formato piriforme ou elíptico nas varreduras longitudinais e arredondado nas transversais. 0 conteúdo mostrou-se anecóico e as paredes finas sem a presença de cálculos e/ ou sedimentos. (Fig.1A). As veias porta e caudal foram identificadas junto ao hilo hepático. Para o acompanhamento do trajeto de cada estrutura foram realizados cortes longitudinais e transversais nas regiões subcostal e intercostal, com auxílio de Doppler colorido. Os ramos portais apareceram como estruturas ramificadas, anecóicas, formato tubular, com paredes hiperecogênicas e as veias hepáticas com aparência similar, entretanto, sem demarcação hiperecóica evidente das suas paredes.

O estômago foi escaneado em posição transversal ao abdome, localizado imediatamente caudal ao fígado. Demonstrou paredes espessas com espessura média de $0,76 \mathrm{~m}$ e pregas de mucosas bem definidas (Fig.1C). 0 piloro foi identificado na margem ventral direita do abdome, com formato levemente cilíndrico.

O baço foi escaneado desde a região cranial esquerda do abdome, imediatamente caudal ao estômago, até a porção medioventral do abdome. Apresentou hiperecogenicidade leve em relação ao fígado e ao córtex renal, textura fina e homogênea, cápsula hiperecóica, contornos regulares, formato alongado e estreito, com apêndice ventral sobre a cauda do órgão. (Fig.1C,D e Fig.2.). As veias esplênicas apareceram com formato de $\mathrm{Y}$ e maior calibre na região hilar, e lúmen de conteúdo anecogênico; as artérias não foram visibilizadas.

Na varredura de todos os animais verificou-se a presença de líquido livre anecóico entre o rim esquerdo e a face ventral do baço. (Fig.1.D). Na necropsia foi verificado que o líquido era límpido de coloração ambar e encontrava-se distribuído por toda a cavidade abdominal. (Fig.2E,F).

Os rins foram visibilizados profundamente na região mesogástrica abdominal, com os rins esquerdo e direito localizados lateralmente à aorta e veia cava caudal, respec- 

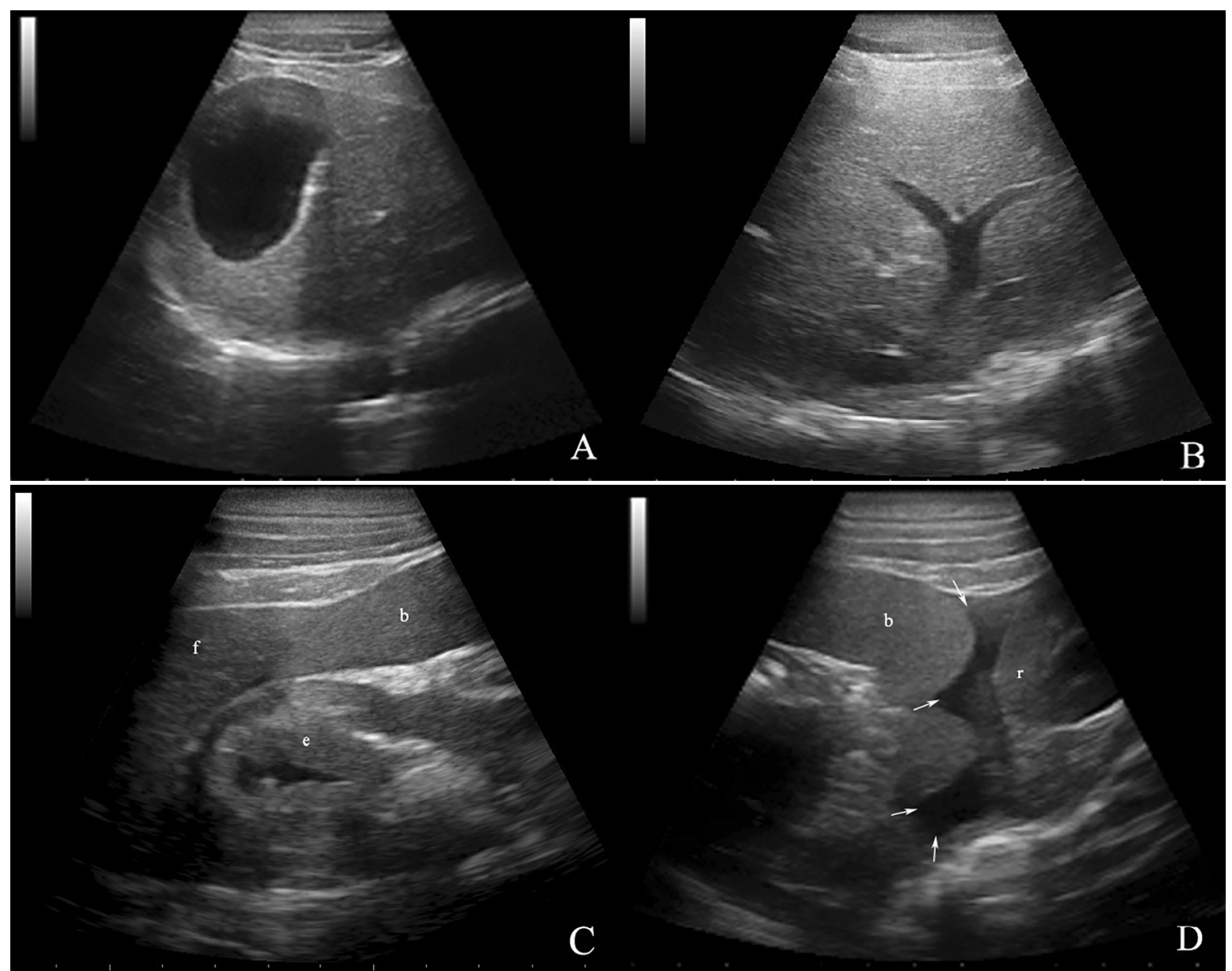

Fig.1. Ultrassonografia do abdome de tamanduá-bandeira. (A) Varredura longitudinal na região hipogástrica direita evidencia fígado e vesícula biliar com paredes delgadas hiperecóicas, conteúdo anecóico e artefato de reforço posterior. (B) Imagem transversal do fígado. (C) Plano sagital na região hipogástrica evidencia estômago com paredes espessas (e) e fígado (f) levemente menos ecogênico do que o baço (b). (D) Varredura longitudinal na região mesogástrica esquerda. Setas indicam presença de líquido livre anecóico entre baço (b) e rim esquerdo(r).

tivamente. Apresentaram formato elíptico sob plano longitudinal, cortical proporcionalmente espessa em relação à medular, com ecogenicidade inferior à do baço (Fig.1D e Fig.2.B) e limites e relações corticomedulares bem definidas. 0 seio renal apareceu como linha ou área hiperecogênica central no plano sagital, sem evidência de distensão da pelve renal e as dimensões médias dos órgãos foram de 6,7 $\mathrm{cm}$ de comprimento e $3,2 \mathrm{~cm}$ de largura para o rim direito e $7,0 \mathrm{~cm}$ de comprimento e $3,3 \mathrm{~cm}$ de largura para o esquerdo. A bexiga urinária apresentou formato piriforme, contornos regulares, paredes delgadas, moderadamente repletas de conteúdo anecóico e localização na região pélvica em posição sagital (Fig.2C,D).

Os testículos dos dois animais examinados localizaram-se no interior da cavidade abdominal, em posição dorsal à bexiga, sob a linha média da coluna vertebral unidos medialmente entre si pelos epidídimos. Ambos apresentaram comprimento e largura médios de $3,9 \mathrm{~cm}$ e $2,9 \mathrm{~cm}$ respectivamente. 0 formato visibilizado foi levemente oval, os contornos regulares ecogênicos, a textura homogênea e hipoecóico em relação aos epidídimos com mediastino central bem definido. Os epidídimos apresentaram formato arredondado na imagem transversal, limites relativamente bem definidos e ecogenicidade elevada em comparação ao parênquima testicular. (Fig.2C,D).

\section{DISCUSSÃO}

A avaliação ultrassonográfica do abdome desses animais revelou várias semelhanças em relação à espécie canina, tanto na sintopia quanto no formato e textura de alguns órgãos. 0 fígado, o estômago, o baço e a bexiga apresentaram localização e sintopia similares (Cartee 1995, König \& Liebich 2006). Entretanto, os rins foram escaneados em projeção mais caudal quando comparado aos rins dos cães e os testículos foram visibilizados no interior da cavidade.

Em cães o rim direito encontra-se normalmente em posição oposta aos corpos das primeiras três vértebras lombares, podendo estar distante cranialmente da última vértebra torácica, já o rim esquerdo é mais caudal e pode apresentar variação na sua posição, já que o órgão está inserido frouxamente pelo peritôneo, por sofrer influência do enchimento do estômago, (Ellenport 1986). Em Tamanduás- Bandeira os rins estão localizados na porção lateral do abdome na região mesogástrica, um dos motivos pelo qual não foi possível escanear o rim direito sob o mesmo plano que o fígado. 0 comprimento e a largura dos rins ob- 

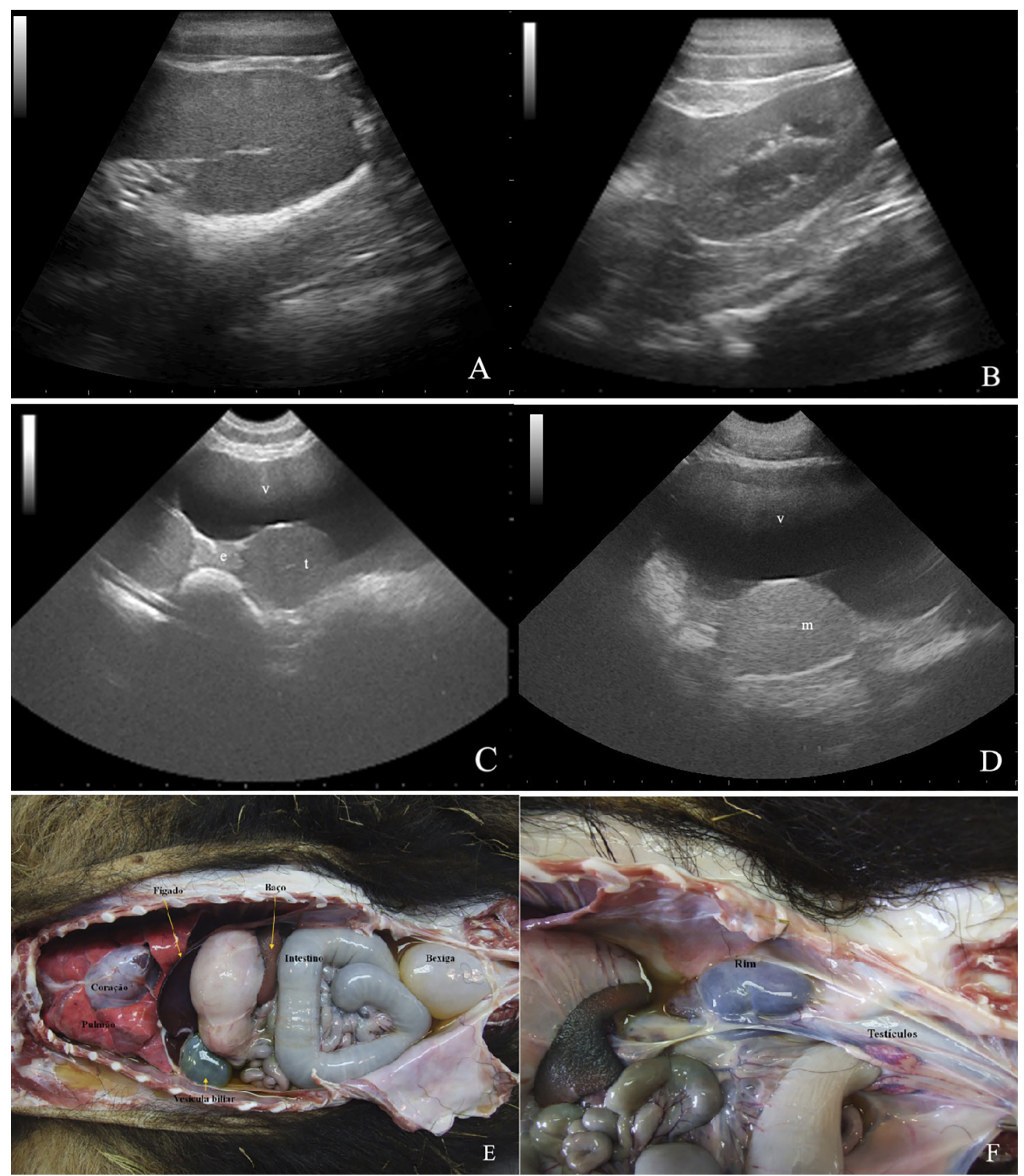

Fig.2. Avaliação ultrassonográfica e achados de necropsia abdominais de tamanduá-bandeira. (A) Visibilização da curvatura na região da cauda do baço em corte transversal na região mesogástrica cranial esquerda. (B) Plano sagital do rim na região mesogástrica esquerda. (C) Plano transversal da vesícula urinária, dos testículos (t) e do epidídimo (e) na região hipogástrica. (D) Testículo em plano longitudinal com mediastino (m) central e hiperecóico. (E) Disposição das vísceras abdominais. (F) Achados de necrópsia evidencia presença de líquido livre de coloração âmbar entre baço e rim esquerdo.

servados nos tamanduás foi similar ao descrito em estudo de mensuração renal em cães (Sampaio \& Araújo 2002), com faixa de peso corpóreo entre 10 e $20 \mathrm{~kg}$, o que indica que o tamanho dos rins dessa espécie é proporcionalmente menor que o dos caninos, já que o peso médio dos animais estudados oscilou em torno de $40 \mathrm{Kg}$.

A distribuição do volume do fígado, a textura e ecogenicidade do órgão, assim como a posição e a aparência ultrassonográfica da vesícula biliar foram muito similares às dos caninos, conforme descrito por Nyland et al. (2002). Assim como é descrito em caninos (Cartee 1995, Konig \& Liebich
2006), o fígado mostrou-se comparativamente menos ecogênico do que o baço (Nyland et al. 2002).

A arquitetura esplênica observada foi similar à observada em caninos (Scholz \& Luerssen 2001, Tannouz 2004, Nyland et al. 2005, Larson 2007). 0 órgão demonstrou formato falciforme, longo e estreito, com a parte ventral mais larga, longitudinalmente esse órgão demonstra forma crescente e triangular. Entretanto, verificou-se em todos os animais um apêndice na região de cauda, localizado na região mesogástrica esquerda, achado não descrito em carnívoros domésticos. 
O acúmulo de líquido anecóico na região localizada entre a face ventral do baço, rim esquerdo e estômago provavelmente é um achado ultrassonográfico normal dessa espécie, uma vez que todos os animais estudados estavam clinicamente saudáveis, bem nutridos e com proteína plasmática dentro da normalidade com valores médios de 6,53/DL (Isis 2002). Entretanto, o acúmulo persistente nessa localização, a despeito das mudanças de decúbito dos animais, não pôde ser explicado, já que durante a necropsia de um exemplar o líquido em quantidade relativamente maior estava distribuído em todas as porções do abdome. Em cães a cavidade peritoneal contém uma pequena quantidade de fluído que serve como lubrificante, no entanto esta quantidade de fluído normalmente não é detectável ao exame ultrassonográfico (D’Anjou 2008).

Apesar do estômago desses animais possuírem localização, sintopia e imagem ultrassonográfica similares às dos caninos, verificou-se que a sua parede nos tamanduás mostrou-se levemente mais espessa. Em média 7,6 $\mathrm{mm}$ frente a 3 a $5 \mathrm{~mm}$ dos caninos (Penninck 2005). 0 espessamento da parede do estômago pode estar correlacionado a dieta desses animais que é baseada em cupins e formigas (Superina 2012). Como os animais estavam em jejum, não foi possível se avaliar a capacidade de preenchimento gástrico.

Um dos achados mais marcantes observados e já bem documentado na literatura (Miranda \& Costa 2007)foi a localização dos testículos e do epidídimo na cavidade pélvica, que associada à fenda genital, comum entre machos e fêmeas, dificulta o trabalho de sexagem Essa localização é completamente distinta de outras espécies de mamíferos, como os caninos domésticos, que detêm em condições fisiológicas os testículos no interior da bolsa escrotal. Nos tamanduás, apesar dessa particularidade, o formato, a ecogenicidade e a textura dos testículos foram bastante similares ao de caninos, conforme descrito por Matton \& Nyland (2005).

O útero e os ovários dos Tamanduás- Bandeira não foram visibilizados. Em caninos muitas vezes não é possível avaliar o útero não gravídico ao exame ultrassonográfico e os ovários também são de difícil detecção, pois depende do tamanho e da fase do ciclo estral em que o animal se encontra. (Janete 2004). Da mesma forma, como não haviam informações anatômicas consistentes sobre estruturas como adrenais e linfonodos dessa espécie, que são pequenas e normalmente de difícil detecção em outros animais, tais órgãos não formam caracterizados.

Como os tamanduás bandeira são animais robustos, com pele bastante espessa e abdome profundo, verificou-se intensa atenuação dos feixes sonoros durante os exames ultrassonográficos, com dificuldade de se examinar estruturas mais profundas, mesmo com transdutor de 3,5 MHz. Em virtude disso, acredita-se que possa ser recomendável uso de transdutores com frequências inferiores à utilizada no presente trabalho, com incremento na qualidade e profundidade da imagem.

Houve dificuldades em se ter acesso a um número maior de animais para o trabalho, porque se tratavam de espécimes ameaçados de extinção, que precisavam ser submetidos à anestesia geral, com todos os riscos inerentes desse tipo de procedimento. Por isso, mesmo com numero reduzido de animais, inferior ao recomendado para estudos dessa natureza, esse trabalho é proposto como uma referência inicial sobre a anatomia ultrassonográfica dessa espécie. Porém estudos adicionais precisam ser conduzidos para corroborar com esses achados ou detalhar aspectos ainda não estudados.

\section{CONCLUSÕES}

O exame ultrassonográfico do abdome do tamanduábandeira demanda uso de configurações de equipamento com maior penetração do feixe ultrassonográfico do que os utilizados em animais de companhia.

Revela similaridades importantes entre morfologia e localização de suas vísceras com a de caninos, como fígado, baço, estômago e bexiga, e diferenças expressivas de outros órgãos como rins e testículos e quantidade de liquido peritoneal livre. Estudos adicionais fazem-se necessários para consolidar as informações obtidas e investigar a morfologia e localização de outras estruturas como ovários, útero, linfonodos e adrenais.

Agradecimentos.- Ao programa de Residência Uniprofissional em Medicina Veterinária pela concessão de bolsa modalidade Residência Médica Veterinária e aos funcionários do Parque Zoológico da Universidade Federal de Mato Grosso pelo suporte.

\section{REFERÊNCIAS}

Bartmann W., Beyer C. \& Wissdorf H. 1991. Topography of the organs of the pelvic cavity and macroscopic and histologic findings of the sex organs of a male giant anteater (Myrmecophaga tridactyla) with regard to fertility]. Berl. Münch. Tierärztl. Wochenschr. 104(2):41-46.

Bartmann W. 1994. Breeding anteaters in captivity. Report Scientific Session 49th Annual Conference IUDZG/The World Zoo Organization in São Paulo, Brazil, p.1-6.

Cartee R.E. 1995. The glands and lymph nodes, p.51-67, 88-235. In: Cartee R.E., Selcer B.A., Hudson J.A., Finn-bodner S., Pamela J. \& Ken M. (Eds), Practical Veterinary Ultrasound. Lea and Feliger Books, New York.

D’Anjou M.A. 2008. Abdominal cavity, lymph nodes, and great vessels, p.445. In: Pennick D., D’Anjo M.A. (Eds), Atlas of Small Animal Ultrasonography. Blackwell Publishing, Iowa.

Endo H., Niizawa N., Komiya T., Kawada S., Kimura J., Itou T., Koie H. \& Sakai T. 2007. Three-dimensional CT examination of the mastication system in the giant anteater. Zoolog. Sci. 24(10):1005-1011.

Ellenport C.R. 1986. Sistema digestivo. p.1445-1484. In: Ibid. (Ed.), Anatomia dos Animais Domésticos. 5a ed. Guanabara Koogan, São Paulo.

Hildebrandt T.B. \& Göritz F. 1998. Use of ultrasonography in zoo animals, p.41-54. In: Fowler M.E. \& Miller R.E. (Eds), Zoo and Wild Animal Medicine: current therapy. 4th ed. W.B Saunders, Philadelphia.

Hildebrandt T.B., Hermes R., Jewgenow K. \& Göritz F. 2000. Ultrasonography as an important tool for the development and application of reproductive technologies in non-domestic species. Theriogenology 53:7384 .

IBAMA 2003. Instituto Brasileiro do Meio Ambiente e dos Recursos Naturais Renováveis. <http://www.mma.gov.br/port/sbf/fauna/index.cfm>

ISIS 2002. Myrmecophaga tridactyla: anteater. International Species Information System, Apple Valley, Minnesota. 3p.

IUCN 2007. Red List of Threatened. Internacional Union for Conservation of Nature and Natural Resources. <http://www.iucnredlist.org/search/ details.php/14224/all>

Janete G.B. 2004. Ultrassonografia do Aparelho Reprodutor Feminino, p.181-189. In: Carvalho C.F. (Ed.), Ultrassonografia em Pequenos Animais. Roca, São Paulo. 
König H.E., Liebich H. \& Sautet J. 2006. Aparelho digestório, p.199-205. In: König H.E. \& Liebich H. (Eds), Anatomia dos Animais Domésticos: texto e atlas colorido. Artmed, São Paulo.

Labruna M.B., Paula C.D., Lima T.F. \& Sana D.A. 2002. Ticks (Acari: Ixodidae) on wild animals from the Porto-Primavera Hydroelectric Power Station area, Brazil. Mem. Inst. Oswaldo Cruz 97(8):1133-1136.

Larson M.M. 2007. The liver and spleen, p.668-687.In: Thrall D.E. (Ed.), Textbook of Veterinary Diagnostic Radiology. 5th ed. Saunders Elsevier, Philadelphia.

Matton J.S. \& Nyland T.G. 2005. Próstata e testículos, p.255-271. In: Nyland T.G. \& Mattoon J.S. (Eds), Ultrassom diagnóstico em pequenos animais. $2^{a}$ ed. Roca, São Paulo.

Miranda F. \& Costa A.M. 2007. Xenarthra (Tamanduá, Tatu, Preguiça), p.402-414. In: Cubas Z.S., Silva J.C.R. \& Catão-Dias J.L. (Eds), Tratado de Animais Selvagens: medicina eterinária. Roca, São Paulo.

Naples N.L. 1999. Morphology, evolution and function of feeding in the giant anteater (Myrmecophaga tridactyla). Zoology 249:19-41.

Nofs S., Abd-Eldaim M., Thomas K.V., Toplon D., Rouse D. \& Kennedy M. 2009. Influenza virus A (H1N1) in giant anteaters (Myrmecophaga tridactyla). Emerg. Infect. Dis. 15(7):1081-1083.

Nyland T.G., Matton J.S., Herrgesell E.J. \& Wisner E.R. 2002. Ultrasonography of the liver, p.93-127. In: Nyland T.G. \& Matton J.S. (Eds), Small Animal Diagnostic Ultrasound. 2nd ed. W.B. Saunders. Philadelphia.

Nyland T.G., Mattoon J.S., Herrgesell E.J. \& Wisner E.R. 2005. Baço, p.131-
138. In: Nyland T.G. \& Mattoon J.S. (Eds), Ultra-Som Diagnóstico em Pequenos Animais. $2^{\text {a }}$ ed. Roca, São Paulo.

Penninck D.G. 2005. Trato gastrointestinal, p.211-232. In: Nyland T.G. \& Mattoon J.S. (Eds), Ultrassom Diagnóstico em Pequenos Animais. $2^{\underline{a}}$ ed. Roca, São Paulo.

Richini-Pereira V.B., Bosco S.M.Z., Theodoro R.C., Barrozo L., Pedrini S.C.B., Rosa P.S. \& Bagagli E. 2009. Importance of xenarthrans in the eco-epidemiology of Paracoccidioides brasiliensis. Bio Med. Central Res. Notes 2:228.

Sampaio K.M.O.R. \& Araújo R.B. 2002. Ultra-sonografia de características lineares e estimativa do volume de rins dos cães. Arq. Bras. Med. Vet. Zootec. 54(3):248-254.

Scholz S. \& Luerssen D.S. 2001. Spleen, p.202-206. In: Natrup C.P., Tobias R. \& Cartee R.E. (Eds), An Atlas and Textbook of Diagnostic Ultrasonography of the Dog and Cat. Manson Publishing, London.

Souza A.L.R., Rezende L.C., Mortoza A.R. \& Ferreira J.R. 2010. Modelo de suprimento sanguíneo do intestino grosso do tamanduá bandeira (Myrmecophaga tridactyla). Ciência Rural 40(3):541-547.

Superina M. 2012. Um passeio pela biologia dos Tamanduás, p.26-37. In: Miranda F. (Ed.), Manutenção de Tamanduá em Cativeiro. Instituto de Pesquisa e Conservação de Tamanduá no Brasil: projeto tamanduá. Cubo, São Paulo.

Tannouz V.S. 2004. Baço, p.86-88. In: Carvalho C.F. (Ed.), Ultrassonografia em Pequenos Animais. Roca, São Paulo. 